\title{
Scaffolding Children's Production of Representations Along the Three Years of ECE: a Longitudinal Study
}

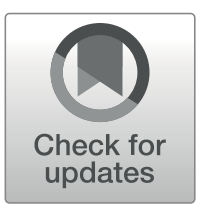

\author{
Sabela F. Monteira ${ }^{1,2}$ (D) María Pilar Jiménez-Aleixandre ${ }^{1}$ (D) $\cdot$ Christina Siry $^{2}$ \\ Published online: 4 May 2020 \\ (C) The Author(s) 2020
}

\begin{abstract}
We report a longitudinal study carried out along 3 years in an early childhood education (ECE) classroom in which we examined children's (aged 3-6) engagement with science representations. The research questions are as follows: (1) How do children's science representations develop from ECE1 to ECE3? (2) What are the features and affordances of the teacher's scaffolding of the production of science representations and how is it facilitated from the first to the third year of ECE? The participants were 21 children and their teacher. The group was involved in long-term science projects that lasted for 5 months each. Sessions $(N=30)$ were recorded and children's drawings $(N=487)$ gathered. Data were analyzed using discourse and content analyses, coupled with an analysis of the intensity of scaffolding. The results indicate that children's representations of science phenomena became more complex along several dimensions. We have identified teacher's scaffolding strategies which supported children's increasing autonomy in producing representations. Implications are drawn for teaching science at the ECE level as well as for further research.
\end{abstract}

Keywords Early childhood education $\cdot$ Representations $\cdot$ Scaffolding

Electronic supplementary material The online version of this article (https://doi.org/10.1007/s11165-02009931-z) contains supplementary material, which is available to authorized users.

Sabela F. Monteira

sfmonteira@gmail.com

1 Departamento de Didácticas Aplicadas, Facultade de Educación, Universidade de Santiago de Compostela, Campus Norte. Avenida Xoán XXIII, S/N, 15782 Santiago de Compostela, Spain

2 Department of Education and Social Work; Faculty of Humanities, Education and Social Sciences, University of Luxembourg, Maison des Sciences Humaines 11, Porte des Sciences,

L-4366 Esch-sur-Alzette, Luxembourg 


\section{Introduction}

Representations are cultural tools and practices, and they are critical in how learners make sense of the world (Fleer and Pramling 2015). At the early childhood level, as children become enculturated to schooling and to the practices of science, they develop the ability to understand, learn, and build through and with representations, a process which is mediated by the context of the classroom. The creation of representations is intentional, as children decide what is important to include in them and, through their use, children also decide that representations stand for something other than themselves.

This study provides a characterization of the ways in which a teacher supported her 3-6year-old pupils' engagement in building representations through repeated and careful scaffolds during early childhood education (ECE) classes and through creating an environment that supports the building of representations. In this paper, the term scaffolds refers to the material and communicative tools the children interact with, which are shaped by the teacher and responsively changed or removed with time, as children become more autonomous. The importance of representations in science learning has been acknowledged both by research (e.g., Lehrer and Schauble 2012) and by policy documents (e.g., the Program for International Student Assessment, PISA framework of the OECD 2016). Although it has been recognized that engagement in this practice can be successfully scaffolded, there is a lack of previous studies about how to scaffold representations at the early childhood level. This research is part of a multiple case study, accompanying three ECE groups (e.g., Monteira and JiménezAleixandre 2016, 2019), with the goal of advancing the field's understandings about how ECE children learn science. This is an appropriate design to study a reality beyond the researcher's control and in which the boundaries within the phenomenon under study and the context are not well-defined (Yin 2003). This paper focuses on one of the groups, which was accompanied for 3 years. We draw from previous longitudinal studies that have documented change over time (e.g., Helldén 2005; Tytler and Peterson 2004). Aside from identifying pathways in the development of understanding in a group of children, these studies have focused on how different science skills and concepts develop over time at the level of the individual, and longitudinal methods served to reveal diverse factors that can affect science learning. Herein, we build on these to turn the analytic focus to the ways in which the individual representations underscore and highlight collective trends over time. In doing so, we seek to arrive at implications for teaching practice geared at scaffolding students' skills and understanding over time.

Our previous studies have shown that young children are capable of quite sophisticated scientific thinking as well as of engaging in complex practices in science education (e.g., Monteira and Jiménez-Aleixandre 2016; Siry 2013). This study examines how teacher scaffolds, meaning the interactions and material tools which facilitate learning, can be emphasized, or de-emphasized, depending on the situation and the needs of the learner; and furthermore, we consider how this variation can be related to children's increasing autonomy. In doing so, we aim to contribute to the literature by analyzing how children's representations developed over time, from the first to the third year of ECE, and how the teacher scaffolded the production of these representations through two research questions:

1. How do children's science representations develop from ECE1 to ECE3? 
2. What are the features and affordances of the teacher's scaffolding of the production of science representations and how is it facilitated from ECE1 to ECE3?

\section{Theoretical Framework}

In this section, we discuss two bodies of research: the practice of building representations and the support of young children's learning with a focus on the role of teachers' scaffolding in early-years science education.

\section{Representations in Early Childhood Education}

A common practice in ECE is that children document their experiences and understandings through visual representations, including drawings and photos, a practice important for supporting young children's learning (Lehrer and Schauble 2012). According to Brooks (2009), drawing is one of the first efforts at abstraction that a child encounters, and reflecting on their own representations allows children to elaborate their ideas further. Danish and Enyedy (2007) and Danish and Phelps (2010) examined how kindergarten children created, evaluated, and revised their science representations. They report that children faced competing constraints which they needed to negotiate, such as those from the teacher, their peers, and the classroom norms. In a study with 5- and 6year-olds (Monteira and Jiménez-Aleixandre 2016) we have found that, prompted by the teacher, children were able to use and reflect upon their own representations of initial ideas, and compare them to the new ones. In doing so, children referred to the evidence involved in the change of their ideas.

Lehrer and Schauble (2005, 2010) found it fruitful to begin with children's metarepresentational capabilities and they deem the invention and use of representational forms, in particular in kindergarten, to be critical steps toward modeling, a practice which is central to science (National Research Council, NRC 2012). According to the National Research Council framework, "modeling can begin in the earliest grades, with students' models progressing from concrete 'pictures' and/or physical scale models (e.g., a toy car) to more abstract representations of relevant relationships in later grades" (NRC 2012, p. 58).

Representations can be considered cognitive tools, and the use and connection between diverse modes of representation of a phenomenon, such as gestures, drawings, or explanations, can enhance learning (Prain et al. 2009; Tytler et al. 2007). Developing these modes also involves being able to move between them, to "shift between alternative ways of representing the same thing" (Olson 2007, p. 22). Bruner (1966) considers that humans represent reality through the use of three increasingly more complex modes of representation: enactive, iconic, and symbolic. The enactive mode involves action; for instance, it is by riding a bicycle that we represent the bicycle to ourselves. In the iconic mode, reality is represented through images that capture the distinctive features of the phenomena represented and serve as prototypes of that kind of phenomena, for instance, a picture of a bicycle. The symbolic mode involves transforming action and image into encoded knowledge, such as language: the word "bicycle." Other authors have discussed the symbolic and iconic nature of representations, giving them different meanings from Bruner's. Thus, Peirce's classic semiotic model (1955) distinguishes among arbitrary symbols that stand for something, such as a word, and images that can be considered icons. For Feinstein (1982), signs are not invented by humans, but merely observed 
and recorded by them, whereas symbols are invented, and their meaning is agreed. A symbol becomes a symbol as a result of someone using it with the goal of denoting or referring (DeLoache 2004), which points out to the social need of mastering the nature of symbols.

As science often involves the study of entities which are not observable, such as energy flows, developing representational competence in science involves becoming able to represent such entities, often using symbols for doing so. Children's production of representations can be fostered by the teacher; and in this paper, we turn the focus onto the teacher's use of scaffolding to explore the ways in which the class' representations emerge and develop over time. In the section that follows, we first discuss how learning is culturally mediated and, thus, it can be supported through cultural tools. Then, we put the focus on tailored support, such as scaffolding.

\section{Supporting Children's Science Learning in ECE}

We position science as a human invention, with rules and valid ways of communication that can be shared within a community. Every child since birth experiences interactions with forces and falling objects. As well In addition to such everyday experiences, learning science involves the immersion in the culture of science, becoming able to understand and use the cultural tools and ways of reasoning associated with it. Thus, science processes and understanding are constructed in interaction (e.g., Siry et al. 2012). Studies about science learning in early childhood within a cultural historical focus examine learning from the perspective that it is culturally mediated in a given environment which has its particular traditions (e.g., Hedegaard 2018; Fleer et al. 2017). As stated by Fleer and Pramling (2015, p. 10), "A cultural-historical reading of science education would position science as a form of cultural knowledge that is historically and collectively formed and understood, rather than as something that is located within the individual."

Early childhood teachers have an important role to play vis-à-vis this cultural production, as they enculturate students into a community of science. Teachers can shape the ways in which children engage in science practices, creating and negotiating meanings in the larger culture that is science. In doing so, they might scaffold children's learning. We understand scaffolding as a wide range of material tools and interactions, shaped by the teacher and responsively changed or removed with time. The term scaffolding was defined by Bruner (1983, p. 60) as "a process of 'setting up' the situation to make the child's entry easy and successful and then gradually pulling back and handing the role to the child as he becomes skilled enough to manage it." There is currently no unified definition of scaffolding (Elbers 2013) and the complexity of this process in cultural, social, and emotional terms has been acknowledged (Renshaw 2013). There is an agreement in that scaffolding must be responsive, as scaffolding involves providing tailored support that meets students' needs. This feature of scaffolding is referred to as contingency by authors such as Reigosa and Jiménez-Aleixandre (2007) or Van de Pol et al. (2010). According to Van de Pol et al. (2010), scaffolding also implies fading, a variation in support until there is a progressive waning out; and transfer of responsibility involves a shift in responsibility from the teacher to the learner, who progressively achieves a higher control of the situation, cognitively, metacognitively, or affectively.

More contemporary readings, based on a CHAT (cultural historical activity theories) perspective of learning, acknowledge that scaffolding does not merely refer to responsive 
teacher help in interactive teacher-student processes, but that it includes a wide range of interactions, such as teacher-student and peer-interactions (e.g., Rojas-Drummond et al. 2013) or interactions mediated by tools (e.g., Warwick et al. 2013).

Dialogue is an important mediator in a classroom setting and it may be expert-novice, such as dialogue involved in teacher-student interactions, or symmetrical, such as peer interactions between students (Hennessy et al. 2016). "Dialogic teaching" has been defined as a type of teaching in which dialogue aims to engage children, stimulating and extending their thinking. In a dialogic classroom, teachers and children listen to each other and the environment is supportive (Alexander 2008). Dialogical approaches support the complexity and multiplicity of the learning environments and place in the center of learning the social interactions and the interactions with material and non-material elements (Ritella and Ligorio 2019). In their review about dialogic teaching, Kim and Wilkinson (2019) have found that, although there are differences in the way this type of teaching is characterized in literature, there is an agreement in its consideration as a general pedagogical approach in which talk becomes a powerful tool that supports learning. Several studies point to the positive effects of this type of teaching approach (e.g., Alghasab et al. 2019; Rojas-Drummond et al. 2013), but we have found few studies regarding the ECE years. In a study with 5-6-year-olds (Monteira and JiménezAleixandre 2016) we found that dialogic teaching played a core role in supporting children's science learning. In particular, children used evidence in sophisticated ways during the course of a science project-using evidence has been reported as being demanding even for high school students. In another study, we found that dialogic teaching supported the production of explanations by 5- and 6-year-olds (Monteira and Jiménez-Aleixandre 2019). The teacher created spaces for discussion and supported children's spontaneous interactions which eventually led to the joint construction of explanations. Nevertheless, teachers might not always notice children's spontaneous interactions that may provide opportunities for learning (Larsson 2013) and, hence, might not foster them. In two studies regarding the scaffolding of science learning in ECE, we have found examples of teacher strategies that can be thought of as responsive dialogue (Eshach et al. 2011; Gustavsson et al. 2016). We agree with the authors in considering this type of interaction as scaffolding, as it is tailored support that is adapted to children's needs. The scaffolding strategies identified in the teacher's discourse involved, for instance, addressing every possible content component and every child in the classroom, bringing together fantasy and play and creating a shared space for learning.

Learning in the ECE classroom is mediated through children's interactions with their teacher, between them and with the material (artifacts) and intellectual tools (concepts) that define this environment (Samuelsson 2018). Scientific representations, such as the ones examined here, can as well be considered cultural tools that mediate learning (Fleer and Pramling 2015). As will be further discussed in the results section, children in this ECE classroom were consistently exposed to representations and often given templates to make their own ones. By appropriating these material tools, each individual within this collective can produce further representations, including both icons and symbols, which hold a meaning within the class culture. That is, the culture of the classroom can provide opportunities for students to further produce cultural tools and resources for learning that have a meaning within this culture, such as children's own scientific representations. 
In this paper, we turn our attention to teacher strategies, including artifacts, spoken communication, and peer interactions, which mediate and support children's ability to produce scientific representations, with increasing autonomy, in the sociocultural setting of the ECE classroom.

\section{Methods}

\section{Methodological Approach}

This longitudinal study is part of a larger research project that was conducted over 3 years in an ECE classroom. Within a qualitative approach, we aim to interpret and understand the meaning given by the participants to their experiences (Merriam 2009). The design is a case study and, due to the teacher's approach, discussed below, the overarching objective was to examine young children's engagement in science. Additionally, given that the group of children remained together from the first year of ECE (3-4 years old) to the third year of ECE (56 years old), we are able to explore changes through the 3 years. The researcher and first author, Sabela Monteira, was a participant observer and, as such, the teacher addressed her in the class talk and prompted children to tell her about the content covered in the science lessons.

\section{Ethical Considerations}

In educational research such as the investigation presented here, in which the participants are the object of study, ethical issues need to be considered (Snape and Spencer 2003). The teacher, the children's parents (as children in the study are under the legal age of 18), and the head of the school were informed of the purposes of the research before it began and their written consent for recording the sessions and collecting children's productions was gathered at the beginning of each of the three school years of this research. In order to ensure the participants' anonymity, the inclusion of information that could lead to their identification was avoided.

\section{Participants and Context}

The participants are one ECE class, comprising 21 children, and their teacher. They are identified with pseudonyms, respecting gender and ethnic origin. The school is located in a bilingual community in which two languages are official for instruction. All pupils in this study understand both and use either one or the other in the class.

Every year, the teacher selects a science topic and carries out a long-term science project in her classroom. By the time of the study, she had over 10 years of professional expertise. She is part of a professional team of six ECE teachers who hold weekly meetings during the school year to learn about a science topic and design together the basis of the science project that is carried out in their classrooms. In the course of the science projects, the pupils share information and learn together about this topic, engaging in inquiry and taking part in scientific practices such as asking questions or using and generating data. Thus, the design of the projects is flexible and adapted to children's interests. The teacher emphasizes children's participation in scientific practices. She asks children to represent the content and experiences of the project through drawings, also emphasizing skills such as how to cut, paste, and color, 
when producing drawings. By the end of the year, she compiles children's drawings in individual portfolios that are later showcased for parents and other community members. As a consequence, she places value on ensuring that the final products from the children are aesthetically pleasing.

In order to answer both research questions, the analysis focuses only on the participants who stayed with the class for the full 3 years of study (21 children and the teacher).

\section{Data Corpus and Collection}

The class was accompanied during the 3 years of the study and data resources were collected throughout that period. Data collection involved immersion of the first author in the classroom, video recording the sessions, collecting student productions, keeping field notes, and carrying out informal interviews.

Due to the nature of the projects, this paper focuses on data from years 1 (6 video-recorded sessions) and 3 (24 video-recorded sessions), during which 482 drawings from the 21 children were collected. Science projects from years 1, about snails, and 3, about clouds, provided children with many opportunities to engage actively in a greater variety of scientific practices than in year 2, about chickens, during which the unit of study was devoted mostly to observation.

Not all the sessions from the first year of study were accompanied by the researcher, as it took some time for the teacher to understand our interest in being in the class for the whole project. Figure 1 summarizes children's production of drawings during both science projects. The timeline corresponds to the months devoted to the project, which in both ECE1 and ECE3 began in January (after Christmas holidays) and ran until June (end of school year). Each drawing task is placed in the moment of the year in which it was made. On the upper part, we have placed codes that represent the 18 drawing tasks made in ECE1 during the Snails Project, $\mathrm{S} 1$ to S18. On the bottom, we have placed the codes for drawings tasks made in ECE3 during the Clouds Project, C1 to C9. For instance, in ECE1 from January until February, children made three drawings related to the science project (S1, S2, and S3), whereas in ECE3 they only made one $(\mathrm{C} 1)$.

Not every child made all the drawings, as absences are common in ECE. Tables 1 and 2 register the number of drawings gathered of each task.

\section{Methods of Analysis}

In order to answer the two research questions, we examined the drawings as well as the classroom oral discourse. The overall analysis that was conducted examined (a) the transcripts of the sessions and (b) children's drawings. This selection was guided by two key understandings: on the one hand, discursive interactions and drawings play a core role in building knowledge (e.g., Fleer and Pramling 2015; Kim and Wilkinson 2019; Samuelsson 2018); on the other hand, in qualitative research, the analysis methods need to be adapted to the

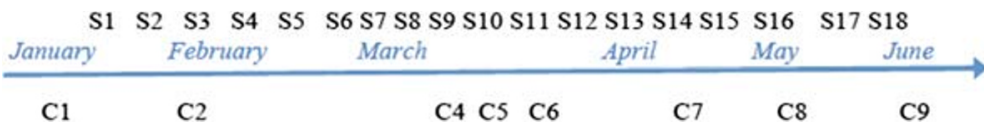

Fig. 1 Timeline of Snails and Clouds Projects' drawings. Upper row: snail drawings (S1-S18). Lower row: cloud drawings (C1-C9) 
Table 1 Drawing tasks in ECE1 and number of drawings collected

\begin{tabular}{|c|c|c|c|c|c|c|c|c|c|c|c|c|c|c|c|c|c|c|}
\hline ECE1 & $\mathrm{S} 1$ & $\mathrm{~S} 2$ & S3 & S4 & S5 & S6 & S7 & S8 & S9 & $\mathrm{S} 10$ & S11 & $\mathrm{S} 12$ & S13 & S14 & S15 & S16 & S17 & S18 \\
\hline$T=326$ & 21 & 19 & 18 & 19 & 19 & 17 & 18 & 18 & 18 & 18 & 18 & 16 & 19 & 16 & 17 & 17 & 20 & 17 \\
\hline
\end{tabular}

phenomena under study (Merriam 2009). Due to its relevance in this classroom, both types of data are appropriate for examining the meanings created by the participants in the study, as children devoted a great part of the sessions to discussing and producing representations. Both representations and discourse synergistically mediate children's learning, although for analytic purposes they are analyzed separately. All the sessions and drawings were examined, and, for the purposes of this paper, we focus on the analysis of the drawings and those episodes of the classroom discourse that took place while children were engaged with representations. Additionally, non-structured interviews were held with the teacher. The analysis was emergent, in the sense that first an overall examination of data resources was carried out, from which analytic themes emerged. Categories and codes were developed in successive iterations, as explained below.

Analysis of the Drawings All 482 drawings were analyzed. From these, 321 correspond to ECE1 (Snails Project, 18 drawing tasks) and 161 to ECE3 (Clouds Project, 9 drawing tasks) (see Appendix for a brief description and sample of each drawing task). We carried out content analysis (Bell 2001) for both research questions and examined structural scaffolding for the second one.

Content analysis (Bell 2001) allowed the elaboration of preliminary categories, in order to identify patterns and differences: (a) between children's drawings in each drawing task; and (b) between drawings from ECE1 to ECE3.

Several cycles of analysis were carried out independently by the three researchers, and categories were successively refined, drawing from the literature. During the first step of this analytic process, we carried out a content analysis (Bell 2001) to identify the content of each drawing and how they were represented in terms of position, coloring, shape, etc. (see Table 3 for an example).

Following on this, a second step emerged from the interaction of the data with the research literature, as we identified entities or relationships represented through iconic and symbolic modes in children's drawings (Bruner 1996; Peirce 1955). In the iconic mode, entities represented physically resemble observable entities, for instance, materials and tools used in an experiment. In the symbolic mode, entities or relationships represented do not physically resemble what they stand for. Symbols are socially created and shared, as their meaning depends on an arbitrary code that has to be learned in order to interpret them, for example, an arrow, or a color code expressing relationships among elements in the drawing; or they may stand for not-observable elements relevant for the phenomena represented: water drops in the air, or a radula in the snail, an internal organ that cannot be observed from the outside. These symbols are introduced and learned through participation in the class culture.

Table 2 Drawing tasks in ECE3 and number of drawings collected

\begin{tabular}{llllllllll}
\hline ECE3 & C1 & C2 & C3 & C4 & C5 & C6 & C7 & C8 & C10 \\
\hline$T=161$ & 17 & 18 & 19 & 18 & 17 & 17 & 16 & 19 & 19 \\
\hline
\end{tabular}


Table 3 The first step of the analytic process: for example, content analysis of three of the C1 drawings (Alma, Ariadna, and Javier, 3 drawings)

\begin{tabular}{|c|c|c|c|c|}
\hline Child & Clouds & Background & $\begin{array}{l}\text { Labeled with child's } \\
\text { name }\end{array}$ & Other variables \\
\hline Alma & $\begin{array}{l}\text { Colored cumuli on the top, with a } \\
\text { landscape }\end{array}$ & No & Yes & Animal \\
\hline Ariadna & $\begin{array}{l}\text { Colored cumuli on the top, without } \\
\text { landscape }\end{array}$ & Blue & No & $\begin{array}{l}\text { Birds and } \\
\text { butterflies }\end{array}$ \\
\hline Javier & $\begin{array}{l}\text { Blue cumuli on the top, without } \\
\text { landscape }\end{array}$ & Blue & No & Truck \\
\hline
\end{tabular}

We examined whether the decisions about which elements to represent or how to represent them were made by the children, the teacher, or through collective discussion. We used data from the transcripts, further discussed in the section about verbal scaffolding, and checked the results with the teacher. Structural scaffolding was identified in children's drawings. Structural scaffolding refers to those elements included by the teacher as part of a template, for instance, fill-in-the-blank or cut-and-paste tasks, as well as to her own intervention in cutting and pasting elements of the representations. This notion draws from Sherin, Reiser, and Edelson's (2004) and Puntambekar and Hübscher's (2010) ideas about expanding the scaffolding metaphor to learning artifacts designed to meet children's needs, the template being such an artifact.

Using this understanding, the data from the first analytic step (see Table 3) were elaborated in this second step, in order to identify, for each content, the mode of representation, the patterns, and differences, as well as clarification of who took the decisions, as shown in Table 4. Due to the great number of productions and limited space, the full analysis is not included, rather the main points are shown via examples (see Tables 3 and 4). Note that Table 3 refers to children's first drawings of the sky (C1), as the one reproduced in Fig. 4; and Table 4 illustrates the analysis of drawings of the

Table 4 The second step of the analytic process: for example, drawing task S5. Snail taste (19 drawings)

\begin{tabular}{|c|c|c|c|c|}
\hline Content & Mode & Patterns & Differences & Decision \\
\hline $\begin{array}{l}\text { Conclusion } \\
\text { (19) }\end{array}$ & Symbolic & Same sentence (19) & Coloring & $\begin{array}{l}\text { Teacher chooses the words } \\
\text { Children decide pasting } \\
\text { order } \\
\text { and coloring }\end{array}$ \\
\hline Cross (18) & Symbolic & Crossing salt (18) & Shape and position & $\begin{array}{l}\text { Teacher asks for it as part } \\
\text { of the task }\end{array}$ \\
\hline Flour (19) & Iconic & Filled with color (18) & Coloring & $\begin{array}{l}\text { Template } \\
\text { Children decide coloring }\end{array}$ \\
\hline Frame (19) & Iconic & Filled with color (18) & Coloring & $\begin{array}{l}\text { Template } \\
\text { Children decide coloring }\end{array}$ \\
\hline Labels (19) & Symbolic & One label per object (19) & Ease to write & $\begin{array}{l}\text { Teacher asks for it as part } \\
\text { of the task }\end{array}$ \\
\hline Pathways (19) & Symbolic & Snail and flour highlighted (18) & Coloring & $\begin{array}{l}\text { Template } \\
\text { Children decide coloring }\end{array}$ \\
\hline Salt (19) & Iconic & Not filled with color (18) & - & $\begin{array}{l}\text { Template } \\
\text { Children decide coloring }\end{array}$ \\
\hline Snail (19) & Iconic & Filled with color (18) & Coloring & $\begin{array}{l}\text { Template } \\
\text { Children decide coloring }\end{array}$ \\
\hline
\end{tabular}


experiment about snails' taste (S5), as the one reproduced in Fig. 6. Both figures are shown in the results section. The analytic steps described above were recursive and through an iterative analysis, the claims described next emerged.

Content analysis is used to examine comparable samples of observable content as it enables being able to identify and compare explicitly visual defined categories (Bell 2001). In order to quantify categories of content, it is necessary to define variables and values. A content variable consists of any dimension or range of option. A variable can have different values, which are elements that belong to the same class. Variables in $\mathrm{C} 1$ drawings (Table 3) correspond to what is represented, for instance, clouds and background; and the different choices of representation account for the values. For instance, for the variable clouds, there are several possible values: colored cumuli on the top, blue cumuli on the top, with/without landscape.

Analysis of the Verbal Discourse The transcripts of the sessions were divided into episodes, corresponding to consecutive turns devoted to the same topic or action (Gee 2014).

First, the organization of the sessions into episodes was essential to carry out the steps of discourse analysis, as it allowed us to examine the meaning of each unit of analysis and interpret how the teacher shaped the discourse. Second, in order to answer RQ2 and drawing from literature on dialogic learning and teaching (e.g., Kim and Wilkinson 2019; Rajala and Akkerman 2019), we examined the episodes with a focus on the teacher objectives that shaped the classroom's dialogue. Through iterative analysis, these interventions were classified into four types, according to what she sought to promote through them: (1) reflection; (2) supporting talking science; (3) legitimizing children's role as knowledge producers and their participation in science; and (4) promoting children's autonomy in discourse (see Table 7, second section of results). The analysis has been carried out in relation to the teacher, although the discourse is collectively created by her and the children given that she played a central role in shaping it.

Second, we focused on the specific strategies the teacher used to support children in carrying out the drawing tasks. The verbal scaffolding provided by the teacher was identified in the transcripts of the episodes in which children were engaged in producing representations, that is, the specific instructions or hints that she used. We employ the term verbal scaffolding drawing from the notions of responsive (Eshach et al. 2011; Gustavsson et al. 2016) and dialogic (Alexander 2008) teaching, approaches in which discourse plays a core role in supporting learning. Drawing from Rojas-Drummond's (2013) ideas about the role of peer's interactions, we also identified "collective scaffolding," that is, interactions between peers that lead to discussions about what and how to represent phenomena and entities in the drawings.

In order to better characterize the teacher's scaffolding, we interviewed her to identify her goals or intentions for what she wanted to achieve with it, and the tools or means she provided to achieve these goals, which is how scaffolding takes place (Van de Pol et al. 2010).

Analysis of the Intensity of Scaffolding in Drawings and Verbal Discourse The analysis draws from studies examining the relevance of the intensity of scaffolding to students' achievement (Van de Pol et al. 2015) and the relation between this variation in scaffolding intensity and students' increasing ease and autonomy (Smit and Van Eerde 2013). In order to examine the intensity of scaffolding, we also examine the differences along the years in the templates provided by the teacher, as we consider these tools that support learning and that are designed by the teacher tailored to meet children's needs. 
Although scaffolding intensity could be considered as a continuum, for analytical purposes, three levels - high, medium, or low — were established. We consider that there is high intensity of scaffolding when the teacher takes the decisions about how and what to draw: (a) she provides a detailed template in which the elements are already depicted and children just color them; (b) she provides children with fill-in-the-blank and cut-and-paste tasks; or (c) she gives children very specific instructions about what and how to draw. We consider low intensity of scaffolding the case when students take the decisions about what and how to draw, either individually or through class discussion with peers. These are cases in which (a) the teacher provides a template that includes only a frame, room for a drawing and for the conclusion; (b) the teacher only chooses the painting technique; (c) the instructions about what and how to draw are very general; and (d) the teacher leaves room for children to discuss and decide what to draw. In between, there is a medium-scaffolded situation in which there is joint responsibility, that is (a) when children make their drawing without teacher's intervention, but afterwards she cuts it and pastes it on a card, and (b) the teacher gives very specific indications about only one of the dimensions in the drawing. Table 5 summarizes the coding categories for the intensity of verbal and structural scaffolding.

Focal Productions All 482 drawings were analyzed as described above. Due to space limitations, we selected tasks from this data set that were the most representative for the sections that follow, in order to illustrate the data analysis as well as the variety in the dimensions analyzed. Trends in the development of all children's representations (across the 482 drawings) are elaborated next in the results and nine drawings from eight children (four girls and four boys) are highlighted, to situate the patterns that emerged from the content analysis and from the examination of structural and verbal scaffolding, with concrete examples from the data corpus. Drawings were selected attending to the following criteria:

- These drawings tasks are representations of (a) initial ideas (S1 and $\mathrm{C} 1$ ); (b) experiments (S4, S5, C4, C5); and (c) domain-specific content (S8, S17, C6).

Table 5 Coding categories of the intensity of structural and verbal scaffolding of drawing tasks

\begin{tabular}{lll}
\hline Intensity & $\begin{array}{c}\text { Structural } \\
\text { High }\end{array}$ & Verbal \\
\hline $\begin{array}{c}\text { The teacher provides a detailed template in } \\
\text { which children's performance is limited to } \\
\text { coloring the elements depicted or drawing } \\
\text { them in a place determined by the teacher }\end{array}$ & $\begin{array}{c}\text { - The teacher gives very specific instructions } \\
\text { about what and how to draw }\end{array}$ \\
- The teacher provides a task in which children's \\
performance is limited to fill-in-the-blank and \\
cut-and-paste actions
\end{tabular}


- They illustrate how the dimensions that emerged from the analysis are materialized in individual productions: i.e., using symbolic and iconic modes of representation, as well as low, medium, and high degrees of scaffolding.

- Regarding the chronology of the tasks in the two projects (snails and clouds), the drawing tasks highlighted in this manuscript were made at different stages throughout both projects (see Fig. 1), and as such the selection of these particular drawings as representative emerged from the analysis.

- According to the teacher's comments as well as the first author's observations, the children whose drawings are presented herein are also representative of the class culture. We chose drawings from four girls and four boys, and their drawings are representative of the range of abilities and experiences present in the class during the study.

\section{Results Regarding Representations Complexity from ECE1 to ECE3}

The results are organized into two sections in order to answer the two research questions.

This section discusses results related to RQ1: How do children's science representations develop from ECE1 to ECE3?

First, we summarize the overall findings from the content analysis of what children represented and how their drawings changed. Second, results from the analysis are discussed, and focal drawings are used to illustrate the three categories of the results which are illustrative of the type of scientific representations that were produced by children: representation of (a) initial ideas, (b) experiments, and (c) domain-specific content. We should clarify the use of the term drawing task and drawing. The first one refers to the task designed by the teacher (e.g., S9, C3); and the second one refers to the individual production of each child when completing this task.

\section{Trends in the Development of Children's Drawings from ECE1 to ECE3}

From the first to the third year of ECE, children took more decisions about what to include in their drawings, and their ability to use both iconic and symbolic modes of representation in them improved, as summarized in Table 6.

Table 6 Modes of representation: changes in children's drawings from ECE1 to ECE3

\begin{tabular}{|c|c|c|}
\hline Dimension & $\operatorname{ECE} 1(N=18)$ & $\operatorname{ECE} 3(N=9)$ \\
\hline $\begin{array}{l}\text { Modes of } \\
\text { representa- } \\
\text { tion }\end{array}$ & $\begin{array}{l}\text { Iconic: } \\
\text {-Introduced by the teacher in } 15 \text { drawing tasks } \\
\text { and by the children in } 3 \text { drawing tasks } \\
\text {-Detail: some body parts missing; accuracy } \\
\text { increases along the school year } \\
\text { Symbolic: } \\
\text { - Introduced by the teacher in the } 18 \text { drawing } \\
\text { tasks }\end{array}$ & $\begin{array}{l}\text { Iconic: } \\
\text { - Introduced by the teacher in } 2 \text { drawing tasks } \\
\text { and used by the children in } 7 \text { drawing tasks } \\
\text { - Detail: small body parts are included; more } \\
\text { accurate } \\
\text { Symbolic: } \\
\text { - Introduced by children in } 4 \text { drawing tasks and } \\
\text { by both the teacher and the children in } 3\end{array}$ \\
\hline
\end{tabular}


In the first year, the children colored symbolic elements introduced by the teacher (see the Appendix for samples of each drawing task referred to in the analysis), such as the arrows used in drawing task S10 to link pictures of the parts of snails' body to the place where they are located in the animal; separation lines in drawing task S14, to separate the land and the sea snails; or the labels as in task S18, with the name of the animals that eat snails. The teacher had a focus on practicing writing, and as such she expected children to identify the content depicted by writing the name besides it. In the third year by comparison, children spontaneously drew and proposed to their peers a variety of symbols, for instance, labels: in 7 out of 18 drawings of the boiling experiment (drawing task $\mathrm{C} 2$ ), children decided to write the name of the instruments depicted. They also represented non-observable entities, such as water drops in the air. For instance, when representing four different measures of water in a glass (C4) over several weeks, Aitor suggested to his peers to draw drops in the air to represent the evaporation process. The water drops were coded as symbolic elements because evaporated water cannot be observed. Several days after producing this drawing, the teacher prompted children to discuss the meanings conveyed in this representation. David explained that he represented the greater decrease in the height of water by drawing a different number of drops (Fig. 2).

Teacher: David, you... here [pointing to David's drawing] ... what did you do? Tell us.

David: That... in each [imperceptible]... as here [pointing] as here it evaporated... as here it evaporated a few [drops]... I put a few droplets. Here, as it evaporated a little more [imperceptible], more droplets... and then here, that evaporated much more... I put more drops here.

This excerpt illustrates David's use of symbols for representing the relationship between water levels as they decrease through the process of evaporation and the related water droplets represented in the air in his drawing. It should be taken into account that, although water drops do only exist in the liquid state, children had also experimented with water heated at boiling temperature and discussed the bulk of steam coming out of

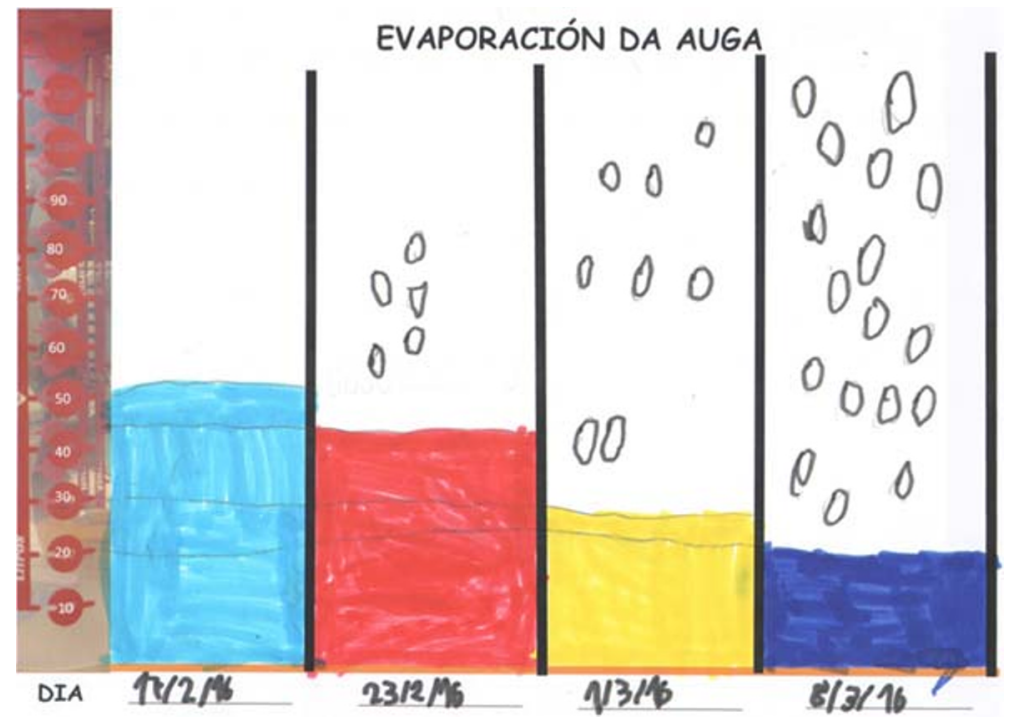

Fig. 2 David's drawing measures, C4 
the pan. They applied the observations from this experience to propose an explanation about how evaporation of water from the glasses could take place based on the idea of little non-observable drops and the teacher allowed them to use this idea in their successive interpretations. Although the teacher introduced the word molecule through educational videos about the states of water, she did not require children to employ it, instead children were speaking about drops being closer to each other in the liquid state than in the gas state, and very close together in the solid state.

Aside from the development of the use of symbolic modes of representation, children's use of the iconic mode also developed. During ECE1, there were changes in the use of iconic modes of representation such as humans and snails: new body parts were included and represented with higher accuracy by the end of the school year. In the second drawing of this year, children represented a human, and only two of the 21 drew the body and eight drew the eyelashes. In contrast, the last drawing of the first year (S18, see Appendix) was produced with great attention to the detail. They were asked to draw animals of their choice that ate snails. Children drew them for instance by representing the six legs of an ant and separating the parts in which its body is divided. Differences between ECE1 and ECE3 are greater: for example, drawings of humans in ECE3 always have a body if there is room for representing it, while in ECE1 they may only have a head, even if there is enough space on the paper to draw more. Furthermore, in ECE3, there is a greater frequency of representation of small parts of the body, such as eyelashes and fingers. ECE3 children also represented many specific and unexpected elements: for instance, including in their drawing the numbers marked on a measuring glass, or reproducing in detail the clothes that the teacher and the researcher were wearing.

\section{Children's Representation of Initial Ideas}

At the beginning of each science project, the teacher asked the children to represent the topic under study, in order to document their initial ideas. One day in ECE1, children found a box with snails when they entered class. The teacher explained that they would have to learn how to look after them and how to feed them. Children discussed what they knew about snails and posed questions about what they wanted to learn, summarized by two displays. She asked them to draw a snail but did not give them specific indications about how to carry out this task,

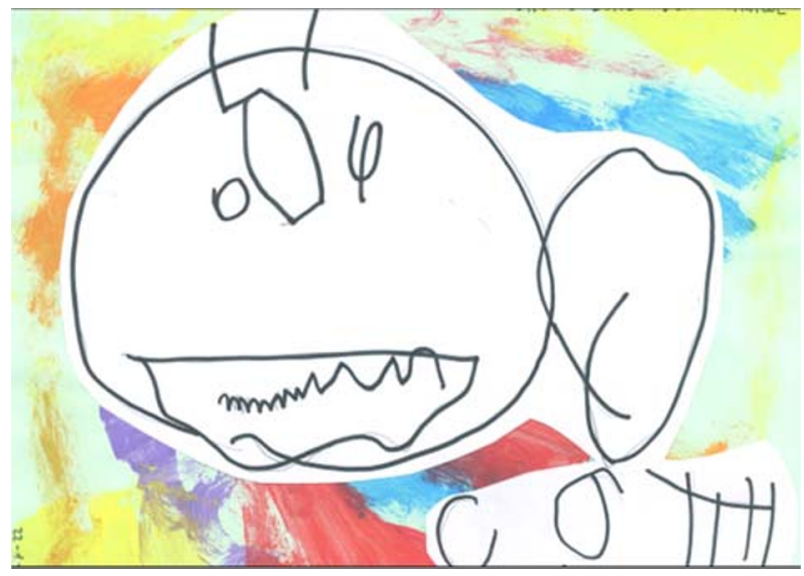

Fig. 3 Mario's first drawing of a snail, S1 
except for labeling it with the word "snail." An example of one of these first drawings (S1) is Fig. 3, Mario's first drawing of a snail. The content analysis reveals many differences between snail drawings, according to children's individual understanding. For instance: children depicted either none, or one or two pairs of tentacles; some drew snails with anthropomorphic features such as limbs and smiles, and some did not; and a few drew the helix on the shell. This drawing, like others from this first year, was modified by the teacher, as she cut out the elements that children had drawn and glued them onto sheets that had been colorfully decorated by the children.

By their third year of schooling, the group was engaged in a project about clouds. At the end of the third session, children produced the first drawing of the project, about the sky (C1). The teacher asked children to draw the sky as they wanted, using colored wet wax crayons and A3 paper. The 17 drawings examined contain cumulus clouds, either on the top part of it (10) or all over the space (7). The openness of this task accounts for the diversity in children's productions: only eight children colored the background. From these, six colored it blue, one red, and another one used several colors. Only five children drew the sky as part of a landscape. Some drew birds (6) and the sun (5), and processes such as rain (5) or storm (5), houses (5), humans (5), trees (4), butterflies (3), flowers (2), an animal (1), a truck (1), and a plane (1). The choice of colors was free. Regarding the coloring, all children but four painted colorfully the clouds and two of them also used non-naturalistic colors for the other entities depicted. From the four children who painted the clouds with naturalistic colors, two used black and white, one used white, and another one used blue. Those who painted the clouds with black color also represented thunder coming out of them. Ariadna's drawing (Fig. 4) focuses completely on the sky and has no ground. It shows colorful clouds, and detailed birds and butterflies.

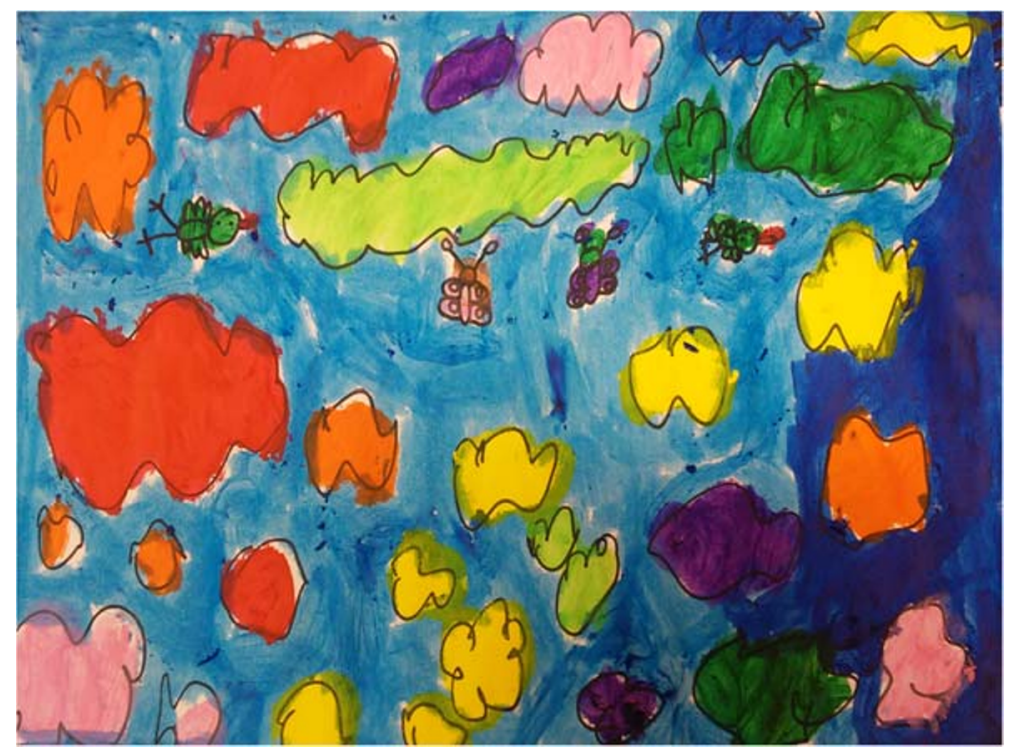

Fig. 4 Ariadna's drawing of the sky, C1 
¿ DE QUE COR É A CACA DOS CARACOIS?
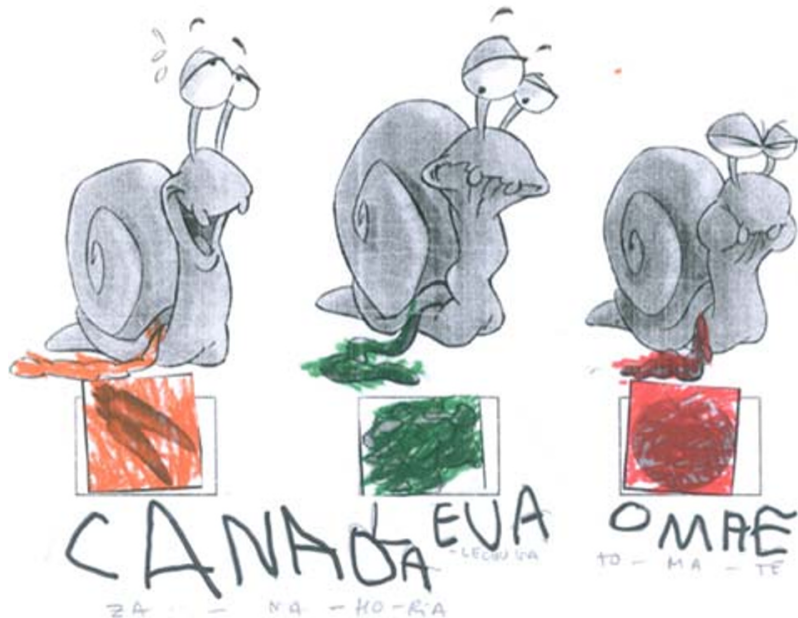

Fig. 5 Romeo's drawing of a snail's poo, S4

\section{Children's Representation of Experiments}

During ECE1, children cleaned the snails' box every day and the teacher prompted them to discuss their observations. After a month, they pointed out that there might be a relationship between the color of the food and the color of the snails' poo, so they experimented giving them food of a single color. They represented their findings with the drawing "Colored poo" (S4). Figure 5 is Romeo's drawing. The teacher asked him to explain his drawing to the researcher, which is part of her pedagogical strategy, in that she acknowledges the role of children as producers of knowledge. Therefore, it was the children's responsibility to explain their drawings, observations, and the pieces of information they brought from home. Romeo explained: "When they eat tomato, the poo comes out red, when they eat lettuce, the poo comes out green and when they eat fish and flour, white poo."

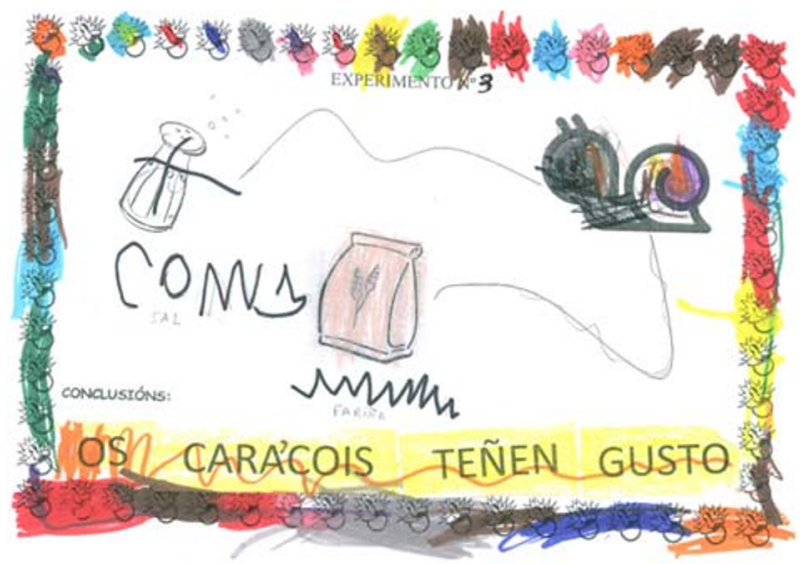

Fig. 6 Andrea's drawing of a snail's taste, S5 
Many symbols are embedded in these drawings. The foods are labeled, and the drawings have a color code indicating the relation between the food and the color of snails' poo, although the foods appear in a different order for different children.

The drawing "Snail taste" (S5 (Fig. 6)), also from ECE1, represents an experiment carried out to answer children's question: Do snails have taste? The experimental procedure involved placing salt and flour on either side of snails and observing their behavior. It was collaboratively designed, with great input from the teacher. When snails went to the flour, they ate it, and when approaching the salt, they turned back. Children interpreted these pieces of evidence as a confirmation that snails have the sense of taste.

In ECE1, the children were provided with a worksheet that had all the elements of the experiment included. As such, their choices were limited to coloring with crayons and to decorating the parts that the teacher had left for them to complete. Children chose different colors to decorate snail and flour, as well as colors for the frame and to highlight the prewritten conclusion. This task allowed children to become familiar with and to use symbolic modes of representation. Symbolic modes in this production are the following: color codes, snail and flour are colored, but not the salt; to highlight the conclusion with a color; to use an " $x$ " to cross out the salt (that snails do not like); and, to trace a line that represents a path which leads the snail to the flour, but not one leading to the salt.

The words that made up the conclusion "snails have the sense of taste" were given to the children, who then chose in the class discussion the order to paste them. The words are in capital letters, the first that the children learned to write. The teacher asked the children to write down the name of both salt and flour underneath each. Children have different writing skills, as this is something they learn in their first year of schooling, and in some cases the teacher wrote the word underneath the label, so that others, including the children's families, could understand.

By ECE3, in order to study cloud formation, the teacher introduced four experiments involving state changes, which were represented by children. We focus on drawing $\mathrm{C} 5$, presenting the "Evaporation" experiment, which involved placing water in an open glass in the classroom and registering the height of the water over several weeks. All the drawings have a conclusion and show a glass with water either coming out from it or in the air. This process

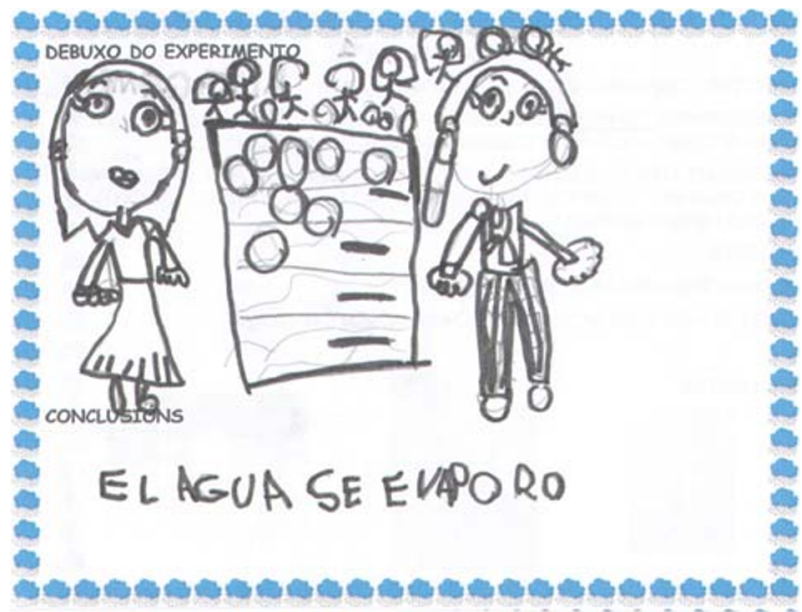

Fig. 7 Azaia's drawing of evaporation, C5 
was not visible: that is, children used a symbolic mode of representation in order to account for the evaporation process, which was the focus of the experiment. Children depicted the water using different symbols: tears, round shapes, lines, thick steam. Three children also drew people involved in the experiment, such as Azaia (Fig. 7). She depicted water vapor coming out from the glass as round shapes.

\section{Children's Representation of Domain-Specific Content}

The next series of drawings illustrate how children learned and represented domain-specific content. In ECE1, children observed that the snails left marks in the food; thus, the children started to look for second-hand information about how snails eat. They found out that snails feed themselves using an organ called radula with which they scrape and dig into the food. Children observed and discussed pictures and saw that the radula is long and straight, with spikes around, called "teeth":

Teacher: And how did they [snails] eat the flour?

Sebastian: With the tongue.

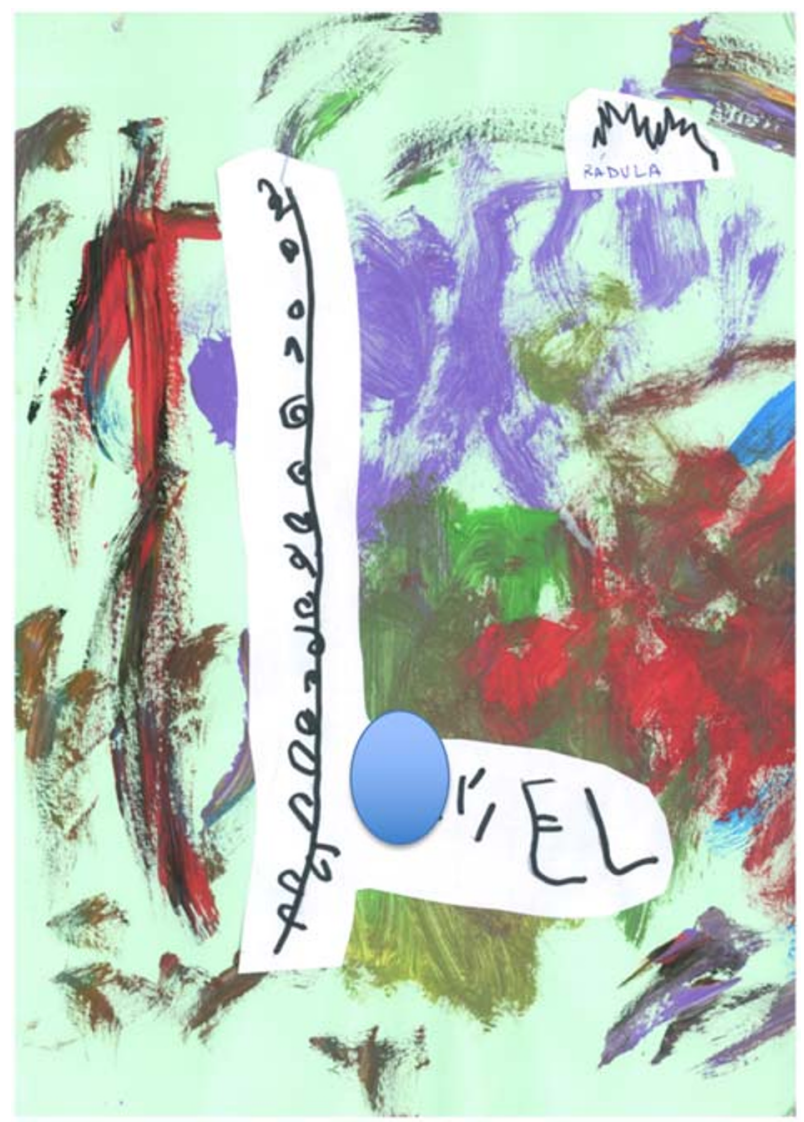

Fig. 8 Aitor's drawing of a snail's radula, S8 


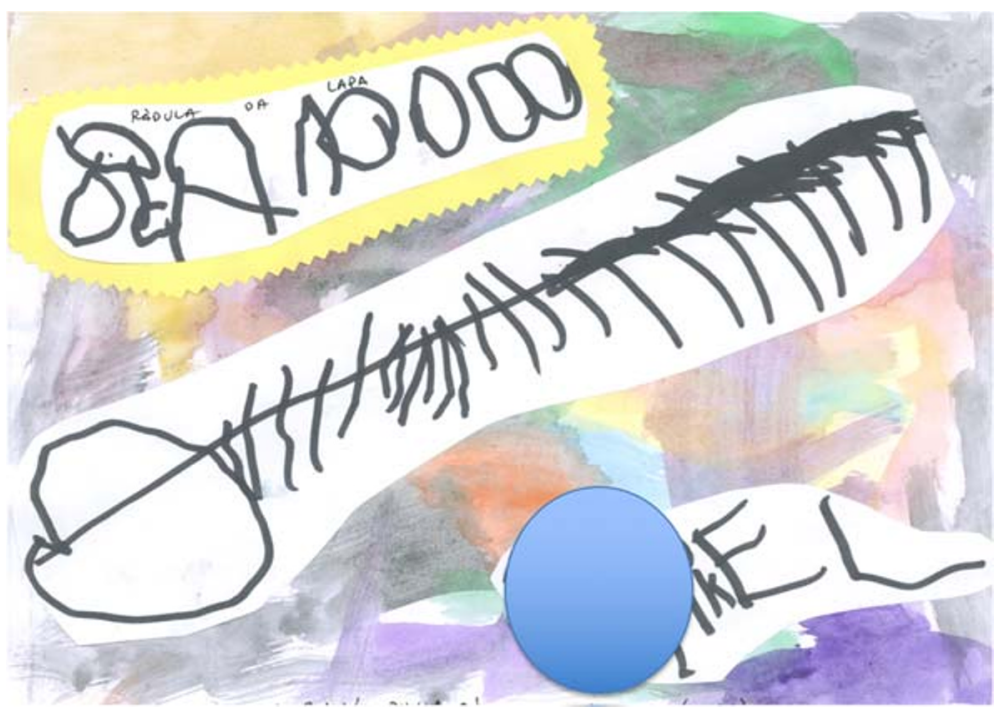

Fig. 9 Aitor's drawing of a limpet's radula, S17

Teacher: What did we see?

Children: The tongue!

Teacher: Tell [researcher's name] what does the snail have in its tongue?

Children: Teeth.

The drawing of the snails' radula (S8) was made in the middle of the second month of the project (February). All children but one represented an organ with "teeth." These were represented either by lines or circles. Twelve children drew the radula like a circle and six drew it like a line. In Aitor's (Fig. 8) drawing, teeth are similar to human ones.

Children had learned that snails and limpets are mollusks and that both have a similar radula. At the beginning of May, the researcher brought a dead limpet to the class to dissect it and show its radula to the children, projecting it with a stereomicroscope and taking pictures of it. Children observed and discussed its parts and colors, identifying its functions. Two weeks later, children discussed the pictures and made drawing S17, "Limpet's radula" (Fig. 9).

These two drawings (Figs. 8 and 9) illustrate how the two practices of (a) using first- and second-hand data and (b) using and producing representations interact in the construction of a concept.

Drawings of "The three states" (C6), from ECE3, were produced after children had enacted a simulation of the three states with their bodies. The teacher prompted: "Each one of you is going to draw on the place for the solid, how the molecules would be placed." Children answered recalling how they had enacted the simulation: "Together." Teacher: "Gas?" Children: "A bit more separated," "Running very fast." In all the drawings, the gas molecules are distributed all over the sheet. The order in which the three states were represented differed. As in the "Colored poo" drawing (S4), the order did not determine the message. Most children represented drops with a round shape, while three children did so with a teardrop shape. Both types of symbols came from the representations used in the class, such as books or the poster of the cycle of water. Two children used the teardrop shape only for one of the states (liquid 


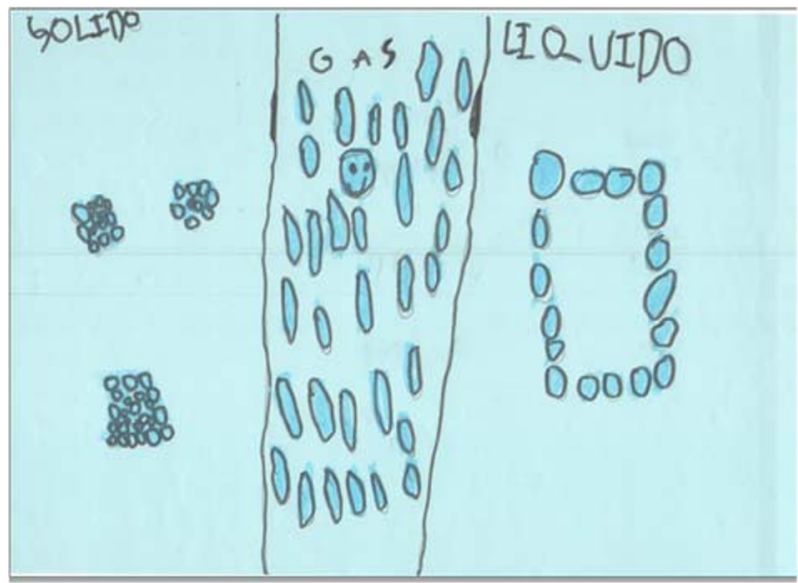

Fig. 10 Marilena's drawing of three states, C6

and gas, respectively) and the round shape for the remaining ones. Regarding the layout of the drops, children represented liquid molecules in a row, either open or closed with a straight or round shape. Four children represented a solid state more than once, as for instance Marilena (see Fig. 10), who drew a representation of molecules in the solid state three times. In all drawings but two, the layout of the molecules in the solid state was a circle. One girl differentiated the three states according to the distance between molecules, not to their layout.

In sum, answering the first research question, the children's representations became increasingly more complex over time, which we will return to in the discussion section.

\section{Results About Changes in Teacher's Scaffolding}

This section discusses findings about the second research question: What are the features and affordances of the teacher's scaffolding of the production of science representations and how is it facilitated from ECE1 to ECE3? In this section, we only focus on how the teacher scaffolded children's production of drawings. First, we describe how the teacher shaped the classroom discourse through her verbal intervention. Second, we focus specifically on how she supported

Table 7 Teacher's strategies used to shape classroom discourse

\begin{tabular}{lc}
\hline Teacher's strategy & Characterization \\
\hline Reflection & $\begin{array}{r}\text { The teacher provides children with many opportunities to } \\
\text { think back about their observations and experiences, to talk } \\
\text { about them, and to reformulate their meaning } \\
\text { The teacher promotes epistemic talk about why and how we } \\
\text { know what we know in a safe and supportive environment } \\
\text { Supporting talking science }\end{array}$ \\
$\begin{array}{l}\text { The teacher acknowledges children's contributions to the } \\
\text { project, such as the data they gather or the pieces of } \\
\text { producers and their participation in science } \\
\text { information they bring to share with the community, } \\
\text { recognizing them as knowledge producers } \\
\text { The teacher consistently intervenes in class talk in order to } \\
\text { promote children's science talk. Her interventions are } \\
\text { tailored and become less frequent from ECE1 to ECE3 }\end{array}$ \\
\hline
\end{tabular}


the production of representations, addressing her scaffolding goals and means; and third, how these were facilitated differently from ECE1 to ECE3.

\section{Features of the Classroom Discourse}

We have identified four strategies the teacher used to shape the classroom discourse, as shown in Table 7. Next, we discuss each of these strategies separately.

By reflection in this context we mean that the teacher promoted children's reflective thinking by providing them with many opportunities to think back about their experiences and to discuss them, so that they were able to reformulate their meanings. Addressing the same topic several times was a feature of this classroom; for example, the topic "slime" was discussed in four out of six recorded sessions of the Snails Project. Similarly to topics being revisited, reflective discussion about experiments also took place not once, but repeatedly. The experiments were carried out and revisited in class discussion several times along each project, so that children could reformulate their explanations and discuss them according to new data available. For instance, the experiment "Making rain" (Clouds Project) was repeated in three different sessions and it was also a topic of further discussion in three related sessions.

The teacher worked towards conditions for children to engage in talking science: she promoted epistemic talk by creating a safe and supportive environment in which children were encouraged to discuss why we know what we know. Children did not need to worry about "wrong" answers, and teachers and children listened to each other. This aspect, according to Alexander (2008), characterizes dialogic teaching. As a result, the environment of the class supported students' engagement in talking science.

Encouraging children's role as knowledge producers involves the teacher's acknowledgment of the value of children's contributions to the project and recognizing their capacity to generate scientific knowledge. The teacher asked the children to show and explain to their classmates the books and information they brought from home to share with the group. When these pieces of information were reviewed in another session, the teacher made explicit who was the child that brought them. In the course of the "Clouds Project," the teacher provided each child with a "Clouds' Observer" credential and an instrument for using in their observations: the "Cloudscope." This instrument consisted of a piece of cardstock with pictures of different types of clouds and a squared hole in the middle through which children framed a part of the sky. Both the credential and the Cloudscope pursued the objective of legitimizing the knowledge produced by children in their observations.

The promotion of autonomy in children's discourse refers to the tailored teacher's interventions in the class talk in order to prompt children to build explanations and support their claims with evidence. The teacher interventions in the class talk became less frequent from ECE1 to ECE3: from an average of 48.5 to $42.55 \%$ of the total turns of speech. By the third year, on many occasions, children spontaneously built explanations, supported their claims with evidence, and addressed topics in greater detail than in the first year. We relate these changes in children's performances, on the one hand, to the teacher's strategies that promoted these ways of participating in the scientific practices, and, on the other hand, to the fact that children are 2 years older and more proficient speakers, so they are capable of building longer and more elaborated sentences. The following two excerpts serve the purpose of illustrating this point. They correspond to children's first observations of snail shells (ECE1) and clouds (ECE3), respectively.

The first excerpt occurs in the context of an observation carried out with the objective of comparing sea and land snail shells. Although the children had already observed the land snail 
shells in previous sessions, this was the first time they observed a sea snail shell in the classroom:

Teacher: Let us see, guys, difference between this snail [land snail shell] and this one [sea snail shell]? Shhhh! Rayssa! Difference. Are the shells the same, Loreto?

Several: No.

Teacher: What are the differences between them?

Loreto: They do not have the same color.

Teacher: They have different colors. What else, Andres, tell me a difference.

Andres: They are not the same.

Teacher: Is this shell like this other shell?

Andres: No.

Teacher: Why? Tell me, Mario.

Mario: Because this shell is [stretched] like this to the top.

It can be noted that children's interventions are short. The teacher facilitates children's reporting on the differences in more detail by repeating their words, that is, legitimizing their claims, and questioning them back, for instance, using "what else" and "why" prompts. After the observation, children made a drawing registering differences between both types of snails (see drawing S14 in Annex).

In ECE3, she still used the same strategies, but children's interventions were longer and spontaneously engaged in building explanations, as illustrated by the following excerpt, corresponding to the first observation of the clouds in the school courtyard:

Teacher: Are they [clouds] all the same?

Several: Noooo!

Non-identified: Some are grey and some others are white!

Teacher: And are they close or far away?

Several: Far away! / Close!

$[\ldots]$

Teacher: And are they [clouds] the same than the first time we looked [at them]?

Several: Noooo!

The teacher calls children's attention and asks them to stop playing.

Table 8 Teacher's scaffolding of children's drawings: goals and means

\begin{tabular}{ll}
\hline Scaffolding goal & Scaffolding means \\
\hline $\begin{array}{l}\text { Learning purpose and features of a science } \\
\text { representation (metacognitive) }\end{array}$ & $\begin{array}{c}\text { - Providing an experiment representation template: a visual } \\
\text { representation, a conclusion, and a frame }\end{array}$ \\
$\begin{array}{ll}\text { Learning to read and to write (cognitive) } \\
\text { - Expecting children to write their own names } \\
\text { - Requiring that children write word labels or paste printed } \\
\text { words in appropriate order } \\
\text { Learning science content (cognitive) }\end{array}$ & $\begin{array}{l}\text { Asking children about the phenomena before representing } \\
\text { them }\end{array}$ \\
$\begin{array}{c}\text { - Asking for accuracy in the drawings } \\
\text { Learning to use both iconic and symbolic modes }\end{array}$ & $\begin{array}{l}\text { Using representations and designing drawing tasks in which } \\
\text { iconic content and symbolic modes of representation are }\end{array}$ \\
Keeping interest in drawing tasks (affective) & $\begin{array}{c}\text { - Public acknowledgment of children's performances when } \\
\text { they draw carefully }\end{array}$ \\
\hline
\end{tabular}


Romeo: A white cloud was over there, and now it is not.

Mario: Because it went going down.

Children's answers are longer and more detailed than in ECE1 and spontaneously include evidence to justify their claims, such as explaining that clouds are different because of their coloring or that the clouds do not look the same because a white cloud has moved. It can be noted that the teacher's prompts help children carry out the observation. She supports them by narrowing the observation focus, pointing to aspects that children are able to understand and manage, because they are known to them, such as clouds' distance to the ground: "And are they close or far away?" This feature distinguishes "purposely observing" from just "looking at" the clouds.

In sum, the teacher promoted a type of discourse that supported and legitimated children's participation in science and indeed created a supportive environment which can be considered scaffolding, as these interventions were modulated along the 3 years.

\section{Scaffolding Children's Production of Representations: Goals and Means}

The features of teacher verbal and structural scaffolding means and their corresponding goals (Van de Pol et al. 2010) regarding the production of drawings are summarized in Table 8. They were identified from three data sources, the analysis of the transcripts, the drawings, and interviews with the teacher. In the course of the project, the teacher combined and adjusted these scaffolding means to each goal, whether metacognitive, cognitive, or affective.

Regarding the cognitive goal of learning science content, the teacher prompted children to discuss the content and think through it before representing it. She also asked them to be accurate, and, consequently, acknowledged children publicly when they drew carefully. For instance, this conversation took place in ECE1 before representing the limpet's radula (see Fig. 9):

Teacher: There [on the screen] it [picture of the limpet's radula] can be seen very well, very well, the tongue is colored how? How is it colored?

Child 1: Orange.

Teacher: It seems orange, right? [...] It looks like... What does it look like?

Child 1: Like an "S".

Child 2: Like a slug.

Child 3: And like a snake. [...]

Teacher: I am going to switch off the screen, I do not want you to see it, I want you to remember it in your heads, so pay attention, because I am going to switch off the screen, right? And I want you to draw it very, very well, right?

Table 9 Intensity of structural and verbal scaffolding in drawing tasks from ECE1 $(N=18)$ to ECE3 $(N=9)$

\begin{tabular}{|c|c|c|c|c|}
\hline \multirow[t]{2}{*}{ Intensity of scaffolding } & \multicolumn{2}{|c|}{$\operatorname{ECE} 1(N=18)$} & \multicolumn{2}{|c|}{$\operatorname{ECE} 3(N=9)$} \\
\hline & Structural & Verbal & Structural & Verbal \\
\hline High & 6 & 2 & 3 & 2 \\
\hline Medium & 8 & 11 & 1 & - \\
\hline Low & 4 & 5 & 5 & 7 \\
\hline
\end{tabular}


The drawings of limpet radula show fewer differences between them than those about snail radula (see Fig. 8) made 3 months earlier, which we interpret as a consequence of the teacher's scaffolding of learning to accurately represent specific content.

Regarding the scaffolding goal of learning to read and write, the teacher instructed the children to draw both the snail (Fig. 8) and limpet radulae (Fig. 9) and to write two labels: their own name (to identify their productions) and "radula" (a title to identify the content), using black pen on a blank sheet of paper. Development of writing along the first school year is evidenced by these two drawings: the word "radula" and the child's name are much more clearly written in the second drawing. The child's name (only a few letters are shown to protect his identity) is more clearly written than "radula," because it is the first word they learn to write. This is a task scaffolded by the teacher and repeated all along the school year.

\section{Modulation of Scaffolding from ECE1 to ECE3}

This section addresses the variations, named "modulation" by Van de Pol et al. (2010), in the intensity of scaffolding. In our use of this term, we consider how the intensity of scaffolding is adapted to each task. Three levels of intensity were identified, high, medium, and low, as represented in Table 5 in the "Methods" section. The teacher varied the intensity of scaffolding in a non-linear way along the years of the study, as summarized in Table 9.

These patterns were identified in the teacher's scaffolding: first, she did not give specific indications for the first drawing in each project, which is coded as low intensity of verbal scaffolding (see Figs. 3 and 4), as her main aim was to explore children's understandings and make comparisons later to make them aware of their growth. Second, in ECE1, she intervened in children's drawings while in ECE3 she did not. In the first year, she cut and pasted their drawings and labels into sheets decorated by them, as in the drawings of snail's and limpet's radulae, and often after the children finished the drawings, the teacher wrote the complete words besides, in order to make them understandable for the children's families (e.g., Fig. 5) when the work was brought home from school. This was identified as medium intensity of structural scaffolding. And third, although the level of intensity varied according to the task, for two of the scaffolding goals summarized in Table 8, scaffolding faded from high to low. These goals are discussed below:

Table 10 Changes in scaffolding means in experiment templates: S5 and C5

\begin{tabular}{|c|c|c|c|}
\hline \multirow[t]{2}{*}{ Scaffolding intention } & \multicolumn{3}{|l|}{ Scaffolding means } \\
\hline & Both S5 and C5 & $\mathrm{S} 5(N=19)$ & $\mathrm{C} 5(N=17)$ \\
\hline $\begin{array}{l}\text { Learning to read and to } \\
\text { write (cognitive) }\end{array}$ & $\begin{array}{l}\text { The teacher prompts } \\
\text { children to discuss about } \\
\text { the conclusion text } \\
\text { (collective scaffolding) }\end{array}$ & $\begin{array}{l}\text { The teacher lets children decide } \\
\text { how to order word labels for } \\
\text { the conclusion sentence } \\
\text { The teacher asks for writing labels }\end{array}$ & $\begin{array}{l}\text { The teacher lets } \\
\text { children decide } \\
\text { and write the } \\
\text { conclusion } \\
\text { sentence }\end{array}$ \\
\hline $\begin{array}{l}\text { Learning to use both } \\
\text { iconic and symbolic } \\
\text { modes of } \\
\text { representation } \\
\text { (cognitive) }\end{array}$ & & $\begin{array}{l}\text { The teacher decides the elements } \\
\text { in the drawing and asks } \\
\text { children to use symbols: color } \\
\text { only the snail and flour; cross } \\
\text { over the salt and color the path } \\
\text { to flour }\end{array}$ & $\begin{array}{l}\text { The teacher lets } \\
\text { children decide } \\
\text { which elements } \\
\text { to draw }\end{array}$ \\
\hline
\end{tabular}


- Learning to use both iconic and symbolic modes of representation: In ECE1, the teacher decided what the content should be, or directly had it in the template, which accounts for the lower differences in what was represented by each child. This strategy allowed the teacher to introduce an array of symbols. In ECE3, the children took the decisions about what to represent, and they drew both icons and symbols.

- Learning to write and read: In all the drawings from ECE1, the teacher stressed labeling elements in representations with their names (e.g., Fig. 8) or writing a title (e.g., Fig. 3). The content analysis of ECE3 drawings reveals differences in the presence of labels within the same task, because including them was the children's choice. For instance, seven children decided to write the name of the tools they used for the experiment "Boiling" in their drawing (C2, see Appendix) and eleven did not. During ECE1, the teacher gave children words that made up the conclusion and asked them to label the elements depicted. Every time children were asked to order words, a discussion preceded the activity to take decisions about what to write and paste. Progressively, the teacher allowed collective scaffolding to take over the teacher's scaffolding. By the third year, children already were writing and reading with ease and the conclusions were collectively decided by the children, and then written down by them on their own.

Drawings S5 (Fig. 6) and C5 (Fig. 7) serve to illustrate the variation in scaffolding summarized in Table 10. Both drawing tasks are on worksheet templates. In S5, the central space for the drawing was already filled by the teacher with the snail, the flour, the salt, and the pathways. C5 also has a frame, with space for the drawing and for the conclusion, but the children chose what to draw in it.

In S5, the children decided how to order the word labels they were given to make up the conclusions. In $\mathrm{C} 5$, the responsibility for producing a claim that can serve as a conclusion was transferred entirely to the children. Through discussion, the children validated one of their peers' proposals: We saw how water evaporated. All the drawings, but one, contain this conclusion. It was written entirely by the children, which accounts for slight differences: "We saw how water evaporated"/Water evaporated." One child also added: "and went to the sky." The teacher asked them to write labels in S5, while in C5 she did not.

For the remaining goals, the scaffolding did not fade. The teacher kept (a) providing children with experiment templates, (b) asking children for accuracy, (c) reviewing the content before representing them, and (d) acknowledging their performances.

\section{Discussion}

This longitudinal study explores how an ECE class and their teacher engaged with representations from the first to the third year of schooling. Representations can be considered learning tools (PérezEcheverría and Scheuer 2009) and their relevance for learning already in the early years of schooling has been largely acknowledged in the literature (e.g., Brooks 2009). What has less often been explored are teaching practices to facilitate children's developing competences in using and making representations at the early childhood level. Although the ways in which teachers scaffold young children's participation in science have been objects of study (e.g., Gustavsson et al. 2016), the contribution of this research is a characterization of the specific strategies used to promote ECE children's engagement in producing representations and how these are more varied and complex as children become increasingly autonomous. It should be noted that in this study we accompany the children for 3 years, during which time their maturity increases. This is not part of our analysis, as we 
are looking to the collective, but, certainly, maturity plays a role in each individual's ability to produce representations. Therefore, this discussion focuses on the trends identified at the collective level, rather than on the individual.

First, we discuss results related to children's production of representations; second, we address the teacher's strategies that fostered this engagement; and, finally, we discuss the implications of the study for both research and practice.

\section{Children's Representations}

In this class, the teacher fostered children's production of representations to illustrate concepts, to register data gathered by themselves, and to represent and build knowledge during the science projects. She prompted them to contribute to the collective construction of knowledge by bringing and discussing their own representations with peers. As shown by the results, children's scientific representations developed from ECE1 to ECE3 in several dimensions:

- Increased autonomy in using symbolic and iconic modes of representation in drawings: The results from the content analysis show that in ECE1 most of the iconic and all of the symbolic modes of representations in children's drawings were introduced by the teacher. In ECE3, children decided what to draw and how to draw it in most of their drawings. This is reflected in greater differences between drawings from the third year. For instance, all the drawings of the experiment about snails' taste, produced in the first year, contain symbolic elements such as a color code and connecting lines, which were introduced by the teacher. In the third year, each child took their own decisions about how to represent the evaporation experiment and included non-observable entities (symbolic mode of representation) as part of it. It should be noted that this was the children's own decisions, as they were not asked to do so by their teacher. The children had acquired the ability to produce their own symbols, as shown by their different choices for representing water drops in this series of drawings. These symbols are appropriated by children because they are cultural tools they have been in touch with along the years that can be found in their classroom and are appropriated to explain concepts in such a setting in which they can be understood. Moreover, these symbols are used to represent science concepts, that is "intellectual tools" (Samuelsson 2018) that are created within the ECE classroom culture in order to account for scientific phenomena.

- The accuracy and attention to the detail in children's representations increased from the first to third year: They used the iconic mode of representation more precisely. For instance, by the third year, they frequently included small body parts, such as eyelashes, in their representations of humans. This can be closely related to the teacher's focus on observation and her prompts while engaged in drawing tasks.

- Children appropriated visual codes to communicate to others: They started learning codes in ECE1, as the teacher provided them with opportunities to interpret representations and included them as part of worksheets. By ECE3, children became autonomous at using and introducing their own ones. For instance, the teacher asked children to use a color code in order to distinguish among evaporating and precipitating water drops in their representation of the water cycle: they were filled in red and blue, respectively. All children but two used this code, some of them with slight variations. For instance, one child drew the blue drops with a red edge and the red drops with a blue one. The two children who did not use this code created a color code of their own to distinguish the two types of drops. 
In our analysis of the drawings, there are several themes that came up in addition to the focus on scientific practices. In the third year, when children autonomously decided which content to draw in the experiment templates, the majority of children did not depict people involved in the experiments, but only the processes observed. For instance, from the 17 drawings of the evaporation experiment, there were only three children who decided to draw one, two (see Fig. 7), and four people involved in the experiment. The different cases, meaning these three children, help us define and better know the pattern: most children dedicated effort to produce a less narrative, more technical drawing, with "only" glasses and drops, enough to convey the meaning of evaporation, documenting the phenomenon according to their class science culture.

Also interesting is the role of color when children decided to use it, a decision which is based in the class culture they have been experiencing. Children mostly used black and white for technical drawings, while using many colors for the open-ended drawings. Sometimes, as in $\mathrm{C} 1$, they had limited color choices available to them, but they used them all in their drawings.

\section{Teacher's Strategies}

The teacher's approach can be considered dialogic. She promoted a type of classroom discourse in which every individual's contributions were relevant for learning and she gave children space for learning. The main dimensions of teachers' discursive approach to support children's participation in science are as follows: recurrence of topics; promoting reflection about observations, experiments, and learning; supporting science talk, acknowledging children's participation in science and their role as knowledge producers; and promoting children's autonomy in discourse. From ECE1 to ECE3, she intervened less in the classroom talk, as children engaged in discussion and provided explanations spontaneously more often.

Aligned with findings from Gustavsson et al.'s (2016) study, we believe that the teacher's view of children's capabilities shaped how she facilitated scaffolding. She believes that children are capable of engaging in science in sophisticated and conscious ways, so she provided synergistic scaffolds (Tabak 2004), that is, she used different scaffolds that enhanced the effect of each other:

- Learning goals: We identified a range of didactic goals the teacher aimed to achieve by scaffolding the drawing tasks. As acknowledged by Renshaw (2013), scaffolding is a complex process covering dimensions including not just the cognitive but also the social and emotional ones. The teacher's goals were metacognitive, such as learning the purposes and features of a scientific representation; cognitive, such as learning to use iconic and symbolic types of content; and affective, such as promoting the children's interest in the tasks. For achieving these goals, she combined structural means, such as designing experiment templates, and verbal means, such as questioning children about the science content and phenomena before representing them.

- Modulation of scaffolding: Regarding how scaffolding was facilitated from ECE1 to ECE3, the variation of scaffolds was not linear. The teacher did not always go from high scaffolding down to low over time, but rather scaffolded when and as needed to meet the task's purposes. For some of the scaffolding goals, though, she faded the intensity of scaffolding in a linear way from ECE1 to ECE3. For instance, in many of the experiment worksheets in ECE1, the children's intervention was limited to coloring the content and pasting in order the words that made up the conclusion sentence. Two years later, in the lower scaffolding conditions, children were given basic templates for representing the 
experiments. The variety of scaffolds seemed to reach most of the children. Children drew all the content, and still met the teacher's requirements about science representations, such as having a central drawing, including details that represented the findings, the experimental procedure or both, and having a conclusion decided and written by them. It should be noted that achieving a high degree of autonomy has been found to be difficult even for high school students (15-16 years old) (Reigosa and Jiménez-Aleixandre 2007). These young children were able to meet the teacher's expectations for engaging in the practices of science, and, over time, were able to do it by themselves and even suggest their own approaches and scaffolding with their peers.

- Legitimation of children's contributions: The teacher provided affective scaffolds, acknowledging children's efforts and contributions. She followed their interests and engaged them in activities as play. Our findings agree with other studies in identifying these strategies are key factors to supporting children's engagement in science (e.g., Sundberg et al. 2016). Affective indicators such as smiley faces in water drops are something we find multiple times across the data (see Fig. 10), or two smiling teachers with children that are sometimes represented in the documents (e.g., Fig. 7). The teacher created the space for those who have different interests and abilities. Even in the higher intensity scaffolding condition, we see evidence of how children bring themselves into the drawing. For instance, even though the teacher decided the structure and the elements represented in the drawing about the three states of water, children found ways to bring themselves in, such as representing the water drops in different dispositions or using a color code.

Scaffolding at different levels and consistently over time afforded children's engagement in representing and developing science understanding. Progressively, children took greater responsibility of their learning because the teacher designed the conditions with these purposes. She created a safe environment for learning.

\section{Implications for Research and Practice}

We accompanied these children and their teacher along a great part of ECE, which allowed for interpreting from a broader perspective the actions, productions, and discourse of the participants in the study. We agree with Danish and Enyedy (2007) that the class norms and interactions with other students and their teacher, among others, are key factors that mediate representational practices, and that these may shift over time. As such, a long-time immersion helped us understand in-depth this complex reality.

The classroom discourse was a powerful tool that the teacher employed to support learning. Dialogic teaching (Kim and Wilkinson 2019) was a core part of the scaffolding strategy of the teacher. With her prompts and questions, she promoted children's autonomy in talking science. We also have identified "collective scaffolding" in relation to the teacher, as she was consistently providing children time to interact and discuss among them. From the beginning of their schooling, she prompted her pupils to discuss and make sense together of the science phenomena they encountered. Along the years, children's interactions became more frequent and they less often needed to be prompted by the teacher. She promoted a safe environment in which children could feel comfortable and their interventions were valued and legitimized.

Long-term immersion in this particular class led to a contextualized understanding of the ways in which these children's engagement with representations developed over time. The distinct difference in the nature of the topics of the projects in ECE1 and ECE3 (snails and 
clouds respectively) led the teacher to propose a diversity of drawing tasks which may have posed a variety of challenges for children and might have affected children's performances. The content in the snails' unit is very concrete, in that children can touch them and directly observe them, while clouds is more abstract in that much of what was discussed is not always evident to the senses. From our analysis however, we highlight the trends in the children's representations across the class, in order to interpret the effect of the teacher's scaffolding on the class collectively, rather than identifying growth in individual performances. Thus, it is not possible to account in detail for the numerous factors that affect individual children's performances, such as maturity. However, we emerge with claims that demonstrate the collective development of children's representations, in particular as related to the teacher's scaffolding. As such, the implications of this in-depth case study connect teaching and teacher education practices.

The breadth of such a large data set allows for carrying out additional analysis and in future work the analysis may focus on the children's individual trends along the 3 years of the study, as the analysis of individual cases in longitudinal designs has been shown to provide a broad understanding of the complexities involved in learning (Helldén 2005). Children with apparently similar understanding might show diverse ways of learning and the different factors that affect them might emerge from close examination of individual data sets. An example of such a longitudinal study is the one carried out by Tytler and Peterson (2004). Besides identifying trends of development in the understanding about evaporation of 12 children that participated in the study from $\mathrm{K}$ to 3 , the authors also put a focus in one of the boys and one of the girls. This analysis allowed them to closely examine how understanding is shaped by children's own narratives of self and the contextual complexities at hand. We use the understanding of the individual performances of the children to reveal collective trends over time in the children's representations.

\section{Concluding Thoughts}

As acknowledged by other authors, the teacher's role (Andersson and Gullberg 2014) and scaffolding (Eshach et al. 2011) are especially important in early ages. This study supports the importance of implementing long-term science projects in ECE in a way that allows children to actively participate in them from the beginning with a certain degree of autonomy. For instance, by bringing an animal that is known to them (the snail), the children were able to contribute by sharing what they already knew, and then, started to build new knowledge, in cooperation, according to their interests. Children's autonomy and ability to engage in science practices benefit from the design of tailored scaffolding through time. As Sinatra and Taasoobshirati (2011, p. 214) point out: "By promoting reflection, cooperative inquiry, critical thinking, and tailoring instruction to promote engagement and conceptual change, science classrooms can support the development of motivated, goal-directed, self-regulated learners." Teaching practices that provide scaffolding to children, as documented and analyzed in this study, can enculturate children into the practices of science, as they become more adept at making and using representations at a young age.

Acknowledgments To the teacher and the children.

Funding Information Sabela F. Monteira and María Pilar Jiménez-Aleixandre's work was supported by the Spanish Ministry of Science, Education and Universities, partly funded by the European Regional Development 
Fund (ERDF), grant code PGC-2018-096581-B-C22. Sabela F. Monteira's work supported by European Science Education Research Association (ESERA) Travel Award 2018.

\section{Compliance with Ethical Standards}

The teacher, the children's parents (as children in the study are under the legal age of 18), and the head of the school were informed of the purposes of the research before it began and their written consent for recording the sessions and collecting children's productions was gathered at the beginning of each of the three school years of this research. In order to ensure the participants' anonymity, the inclusion of information that could lead to their identification was avoided.

Open Access This article is licensed under a Creative Commons Attribution 4.0 International License, which permits use, sharing, adaptation, distribution and reproduction in any medium or format, as long as you give appropriate credit to the original author(s) and the source, provide a link to the Creative Commons licence, and indicate if changes were made. The images or other third party material in this article are included in the article's Creative Commons licence, unless indicated otherwise in a credit line to the material. If material is not included in the article's Creative Commons licence and your intended use is not permitted by statutory regulation or exceeds the permitted use, you will need to obtain permission directly from the copyright holder. To view a copy of this licence, visit http://creativecommons.org/licenses/by/4.0/.

\section{References}

Alexander, R. J. (2008). Towards dialogic teaching. Rethinking classroom talk (4th ed.). York: Dialogos.

Alghasab, M., Hardman, J., \& Handley, Z. (2019). Teacher-student interaction on wikis: fostering collaborative learning and writing. Learning, Culture and Social Interaction, 21, 10-20. https://doi.org/10.1016/j. lcsi.2018.12.002.

Andersson, K., \& Gullberg, A. (2014). What is science in preschool and what do teachers have to know to empower children? Cultural Studies of Science Education, 9(2), 275-296. https://doi.org/10.1007/s11422-012-9439-6.

Bell, P. (2001). Content analysis of visual images. In T. Van Leeuwen \& C. Jewitt (Eds.), Handbook of visual analysis (pp. 10-34). Thousand Oaks: Sage.

Brooks, M. (2009). Drawing, visualisation and young children's exploration of "big ideas". International Journal of Science Education, 31(3), 319-341.

Bruner, J. S. (1966). Toward a theory of instruction. Cambridge: Belkapp Press.

Bruner, J. (1983). Child's talk. New York: Norton.

Bruner, J. (1996). The culture of education. Cambridge: Harvard University Press.

Danish, J. A., \& Enyedy, N. (2007). Negotiating representational mediators: how young children decide what to include in their science representations. Science Education, 91(1), 1-35.

Danish, J. A., \& Phelps, D. (2010). Representational practices by the numbers: how kindergarten and first-grade students create, evaluate, and modify their science representations. International Journal of Science Education, 33(15), 2069-2094. https://doi.org/10.1080/09500693.2010.525798.

DeLoache, J. S. (2004). Becoming symbol-minded. Trends in Cognitive Sciences, 8(2), 66-70.

Elbers, E. (2013). Conceptualising and grounding scaffolding in complex educational contexts. Learning, Culture and Social Interaction, 2, 1-2. https://doi.org/10.1016/j.lcsi.2012.12.002.

Eshach, H., Dor-Ziderman, Y., \& Arbel, Y. (2011). Scaffolding the "scaffolding" metaphor: from inspiration to a practical tool for kindergarten teachers. Journal of Science Education and Technology, 20, 550-565. https://doi.org/10.1007/s10956-011-9323-2.

Feinstein, H. (1982). Meaning and visual metaphor. Studies in Art Education, 23(2), 45-55.

Fleer, M., Veresov, N., \& Walker, S. (2017). Re-conceptualizing executive functions as social activity in children's playworlds. Learning, Culture and Social Interaction, 14, 1-11. https://doi.org/10.1016/j. lcsi.2017.04.003.

Fleer, M., \& Pramling, N. (2015). A cultural-historical study of children learning science: foregrounding affective imagination in play-based settings. Amsterdam: Springer.

Gee, J. P. (2014). An introduction to discourse analysis: theory and methods (4th ed.). London: Routledge.

Gustavsson, L., Jonsson, A., Ljung-Djärf, A., \& Thulin, S. (2016). Ways of dealing with science learning: a study based on Swedish early childhood education practice. International Journal of Science Education, 38(11), 1867-1881. https://doi.org/10.1080/09500693.2016.1220650. 
Hedegaard, M. (2018). Children's perspectives and institutional practices as keys in a wholeness approach to children's social situations of development. Learning, Culture and Social Interaction. https://doi. org/10.1016/j.lcsi.2018.04.008.

Helldén, G. (2005). Exploring understandings and responses to science: a program of longitudinal studies. Research in Science Education, 35(1), 99-122.

Hennessy, S., Rojas-Drummond, S., Higham, R., Márquez, A., Maine, F., María Ríos, R., García-Carrión, R., Torreblanca, O., \& Barrera, M. (2016). Developing a coding scheme for analysing classroom dialogue across educational contexts. Learning, Culture and Social Interaction, 9, 16-44. https://doi.org/10.1016/j. lcsi.2015.12.001.

Kim, M., \& Wilkinson, I. A. G. (2019). What is dialogic teaching? Constructing, deconstructing, and reconstructing a pedagogy of classroom talk. Learning, Culture and Social Interaction, 21, 70-86. https://doi.org/10.1016/j.lcsi.2019.02.003.

Larsson, J. (2013). Children's encounters with friction. Friction understood as a phenomenon of emerging science and as 'opportunities for learning. Journal of Research in Childhood Education, 27(3), 377-392. https://doi.org/10.1080/02568543.2013.796335.

Lehrer, R., \& Schauble, L. (2005). Developing modeling and argument in elementary grades. In T. A. Romberg, T. P. Carpenter, \& F. Dremock (Eds.), Understanding mathematics and science matters (pp. 29-54). Mahwah: Erlbaum.

Lehrer, R., \& Schauble, L. (2010). What kind of explanation is a model? In M. K. Stein \& L. Kucan (Eds.), Instructional explanations in the disciplines (pp. 9-22). Dordrecht: Springer.

Lehrer, R., \& Schauble, L. (2012). Seeding evolutionary thinking by engaging children in modeling its foundations. Science Education, 96, 701-724.

Merriam, S. B. (2009). Qualitative research: a guide to design and interpretation. San Francisco: Jossey-Bass.

Monteira, S. F. \& Jiménez-Aleixandre, M. P. (2016). The Practice of Using Evidence in Kindergarten: The Role Of Purposeful Observation. Journal of Research in Science Teaching, 53(8)1232-1258. https://doi. org/10.1002/tea.21259.

Monteira, S. F., Jiménez Aleixandre, M. P. (2019). ¿Cómo llega el agua a las nubes? Construcción de explicaciones sobre cambios de estado en educación infantil. Revista Eureka sobre Enseñanza y Divulgación de las Ciencias, 16(2), 2101. https://doi.org/10.25267/Rev_Eureka_ensen_divulg_cienc.2019.v16.i2.2101.

National Research Council. (2012). A framework for K-12 science education: Practices, crosscutting concepts, and core ideas. Washington, DC: National Academies Press.

Olson, D. R. (2007). Jerome Bruner: the cognitive revolution in educational theory. London: Continuum Press.

Organisation for Economic Co-operation and Development (OECD). (2016). PISA 2015 Assessment and analytical framework. science, reading, mathematic and financial literacy. https://doi.org/10.1787 /19963777 (retrieved April 2017).

Peirce, C.S. (1955) Logic as semiotic: the theory of signs. In (Buchler, J.J., ed.) (98-119) The philosophical writings of Peirce. Dover.

Pérez-Echeverría, M. P., \& Scheuer, N. (2009). External representations as learning tools: an introduction. In Andersen, C., Scheuer, N., Pérez-Echeverría, M. P. \& Teubal, E. (Eds.) (1-19). Representational systems and practices as learning tools. Rotterdam: Sense Publishers.

Prain, V., Tytler, R., \& Peterson, S. (2009). Multiple representation in learning about evaporation. International Journal of Science Education, 31(6), 787-808. https://doi.org/10.1080/09500690701824249.

Puntambekar, S., \& Hübscher, R. (2010). Tools for scaffolding students in a complex learning environment: what have we gained and what have we missed? Educational Psychologist, 40(1), 1-12. https://doi.org/10.1207 /s15326985ep4001_1.

Rajala, A., \& Akkerman, S. F. (2019). Researching reinterpretations of educational activity in dialogic interactions during a fieldtrip. Learning, Culture and Social Interaction, 20, 32-44. https://doi.org/10.1016/j.lcsi.2017.10.006.

Reigosa, C; Jiménez-Aleixadre, M. P. (2007). Scaffolded problem solving in the physics and chemistry laboratory: Difficulties hindering students' assumption of responsibility. International Journal of Science Education, 29, 307-329. https://doi.org/10.1080/09500690600702454.

Renshaw, P. D. (2013). The social cultural and emotional dimensions of scaffolding. Learning, Culture and Social Interaction, 2, 56-60. https://doi.org/10.1016/j.lcsi.2013.01.002.

Ritella, G., \& Ligorio, B. (2019). Dialogical approaches to learning: from theory to practice and back. Learning, Culture and Social Interaction, 20, 1-3. https://doi.org/10.1016/j.lcsi.2019.02.001.

Rojas-Drummond, S., Torreblanca, O., Pedraza, H., Vélez, M., \& Guzmán, K. (2013). 'Dialogic scaffolding': enhancing learning and understanding in collaborative contexts. Learning, Culture and Social Interaction, 2, 11-21. https://doi.org/10.1016/j.lcsi.2012.12.003.

Samuelsson, R. (2018). Children's explorations of the concept of spinning in preschool: science learning in mediated activity. Learning, Culture and Social Interaction, 17, 90-102. https://doi.org/10.1016/j. lcsi.2018.01.002. 
Sherin, B., Reiser, J., \& Edelson, D. (2004). Scaffolding analysis: extending the scaffolding metaphor to learning artifacts. The Journal of the Learning Sciences, 13(3), 387-421.

Siry, C., Ziegler, G., \& Max, C. (2012). "Doing science" through discourse-in-interaction: Young children's science investigations at the early childhood level. Science Education, 96, 311-326. https://doi.org/10.1002 /sce.20481.

Siry, C. (2013). Exploring the complexities of children's inquiries in science: Knowledge production through participatory practices. Research in Science Education, 43, 2407-2430. https://doi.org/10.1007/s11165-0139364-z.

Sinatra, G. M., \& Taasoobshirazi, G. (2011). Intentional conceptual change: The self-regulation of science learning. In B. Zimmermann \& D. Shunk (Eds.), Handbook of self-regulation of learning and performance (pp. 203-216). New York, NY: Routledge.

Smit, J., \& Van Eerde, D. (2013). What counts as evidence for the long-term realisation of whole-class scaffolding? Learning, Culture and Social Interaction, 2, 22-31. https://doi.org/10.1016/j.lcsi.2012.12.006.

Snape, D., \& Spencer, L. (2003). The foundations of qualitative research. In J. Ritchie \& J. Lewis (Eds.), Qualitative research practice (pp. 1-23). Thousand Oaks: Sage.

Sundberg, B., Areljung, S., Due, K., Ekström, K., Ottander, C., \& Tellgren, B. (2016). Understanding preschool emergent science in a cultural historical context through activity theory. European Early Childhood Education Research Journal, 24(4), 567-580.

Tabak, I. (2004). Synergy: a complement to emerging patterns of distributed scaffolding. Journal of the Learning Sciences, 13(3), 305-335. https://doi.org/10.1207/s15327809j1s1303_3.

Tytler, R., Prain, V., \& Peterson, S. (2007). Representational issues in students learning about evaporation. Research in Science Education, 37(3), 313-331.

Tytler, R., \& Peterson, S. (2004). Young children learning about evaporation: a longitudinal perspective. Canadian Journal of Science, Mathematics and Technology Information, 4(1), 111-126.

Van de Pol, J., Volman, M., \& Beishuizen, J. (2010). Scaffolding in teacher-student interaction: a decade of research. Educational Psychology Review, 22(3), 271-296.

Van de Pol, J., Volman, M., Oort, F., \& Beishuizen, J. (2015). The effects of scaffolding in the classroom: support contingency and student independent working time in relation to student achievement, task effort and appreciation of support. Instructional Science, 43(5), 615.

Warwick, P., Mercer, N., \& Kershner, R. (2013). 'Wait, let's just think about this': using the interactive whiteboard and talk rules to scaffold learning for co-regulation in collaborative science activities. Learning, Culture and Social Interaction, 2, 42-51. https://oi.org/10.1016/j.lcsi.2012.12.004.

Yin, R. (2003). Case study research: Design and methods (3rd edition). Thousand Oaks, CA: Sage Publications.

Publisher's Note Springer Nature remains neutral with regard to jurisdictional claims in published maps and institutional affiliations. 